\title{
Malignant Pleural Effusion
}

National Cancer Institute

\section{Source}

National Cancer Institute. Malignant Pleural Effusion. NCI Thesaurus. Code C9432.

A collection of fluid in the pleural cavity as a result of malignant disease. Malignant pleural effusion fluid often contains free-floating malignant cells. --2004 